\title{
Structural and Optical properties of Chemically Deposited CdS Thin Films
}

\author{
Raghad Y. Mohammed ${ }^{1}$, S. Abduol ${ }^{1}$, Ali M. Mousa ${ }^{2, *}$ \\ ${ }^{1}$ Department of Physics, University of Dohuk, 38 Zakho Street, 1006 AJ Duhok, \\ Kurdistan Region, Iraq \\ ${ }^{2}$ Material Research Unit, Department of Applied Sciences, University of Technology, \\ Baghdad, Iraq \\ *E-mail address: alzuhery51@yahoo.com
}

\begin{abstract}
Polycrystalline Cadmium sulfide (CdS) films were deposited onto Corning glass substrates from alkaline solutions containing $\mathrm{CdCl}_{2}, \mathrm{KOH}, \mathrm{Na}_{3} \mathrm{C}_{6} \mathrm{H}_{5} \mathrm{O}_{7}$ and $\mathrm{CS}\left(\mathrm{NH}_{2}\right)_{2}$ at different deposition times (10, 20, 30, 40 and $50 \mathrm{~min})$, bath temperatures $\left(80 \pm 2{ }^{\circ} \mathrm{C}\right)$ and different concentration of the reactants. A comparative study was performed out on thin film via optical transmission and X-ray diffraction (XRD) measurements. The results which reveal that the deposition time has a profound influence on the growth rate and band gap of the deposited layers. Diffraction data was used to evaluate the lattice parameter, grain size, average strain, number of crystallites per unit area and dislocation density in the film are calculated.
\end{abstract}

Keywords: Cadmium sulfide films; chemical bath deposition; XRD

\section{INTRODUCTION}

Cadmium sulfide $(\mathrm{CdS})$ has been emerged as an important transparent conducting semiconductor for thin film CdTe and $\mathrm{CuInSe}_{2}$ heterojunction solar cells [1-4]. Among all thin film deposition methods, chemical bath deposition (CBD) is the simplest one that offers great scope for large area fabrication. Solar cell efficiency as high as $16.5 \%$ has been reported for $\mathrm{CdS} / \mathrm{CdTe}$ thin film solar cells by using $\mathrm{CBD} \mathrm{CdS}$ films [5]. Most films deposited by CBD adopting the continuous dipping approach where the substrate remains in the reaction bath [6], although a the multiple dip approach had been reported [7]. There are a growing number of reports on using the deposition of $\mathrm{CdS}$ films from an aqueous solution using $\mathrm{CdCl}_{2}$ salt. Little known about the influence of deposition conditions. Therefore, the study of $\mathrm{CdS}$ with respect to different growing conditions is a matter of high importance. This is an aspect of great importance because it is well known that structural properties affect the optical and electrical properties of deposited layer and hence device efficiency and its lifetime. In this work, $\mathrm{CdS}$ thin films were prepared by the $\mathrm{CBD}$ technique under different growing conditions. The band gap energy, optical and crystalline structure of the CdS films were investigated as a function of the growing conditions [17-22]. 


\section{EXPERIMENTAL WORK}

\section{1. Substrate cleaning}

The substrate used is glass slides with size of $\left(75 \times 25 \times 1 \mathrm{~mm}^{3}\right)$. which were first cleaned in distilled water, followed it rinsing in chromic acid (for one day), to introduce nucleation centers.

\section{2. Solution preparation}

Films were deposited on glass slides using $12 \mathrm{ml}$ of $0.05 \mathrm{M}\left(\mathrm{CdCl}_{2}\right)$ mixed slowly with $20 \mathrm{ml} \mathrm{Na} \mathrm{C}_{6} \mathrm{H}_{5} \mathrm{O}_{7}$ at room temperature with continuous stirring. Then $5 \mathrm{ml}$ of $0.5 \mathrm{KOH}$ is added. Substrates immersed in a beaker containing the reaction mixture placed in a water bath at temperature $80 \pm 2{ }^{\circ} \mathrm{C}$ with continuous stirring, $10 \mathrm{ml}$ of $0.5 \mathrm{M}$ thiourea was then added. Substrates were taken out after a suitable time; they were washed with distilled water and ultrasonic agitation to remove the porous cadmium sulfide over layer, then dried in hot air. All the samples were prepared at $\mathrm{pH}=11$. The same deposition process is repeated by varying the concentration of $\mathrm{CdCl}_{2}$ used.

\section{3. Thickness measurement}

Film thickness is measured by optical interferometer method using $\mathrm{He}-\mathrm{Ne}$ Laser $(0.632 \mu \mathrm{m})$, the thickness is determined using the formula:

$$
d=\frac{\Delta x}{x} \frac{\lambda}{2}
$$

where $\mathrm{X}$ is fringe width, $\Delta \mathrm{x}$ is the distance between two fringes and $\lambda$ is the wavelength of laser light.

\section{4. Structure Measurements}

X-ray diffraction taken by (Philips 1140) diffractometer of $\lambda=1.54 \AA$ from $\mathrm{Cu}-\mathrm{K} \alpha$ operating at $36 \mathrm{kV}-18 \mathrm{~mA}$ and compared with the ASTM cards number 83. The lattice parameters, a and $\mathrm{c}$ of the unit cell were evaluated from the relation $[8,9]$,

$$
\frac{1}{d^{2}}=\frac{4}{3} \frac{h^{2}+h k+k^{2}}{a^{2}}+\frac{l^{2}}{c^{2}}
$$

where $d$ is the inter planar spacing. The grain size (D) values are calculated using the Scherrer Formula [7]:

$$
D=\frac{0.9 \lambda}{\beta \cos \theta}
$$


where $\beta$ is the full-width at half-maximum (FWHM) of the peak and $\theta$ is the Bragg angle. The dislocation density $(\delta)$ estimated using the equation [8]:

$$
\delta=\frac{1}{D^{2}}
$$

The number of crystallites per unit area $(N)$ and the strain $(\in)$ of the films were determined with the use of the following formulae [10]:

$$
\begin{gathered}
N=\frac{t}{D^{3}} \\
\in=\frac{\beta \cos \theta}{4}
\end{gathered}
$$

\section{5. Optical Properties}

Optical properties for CdS films depend on the dielectric constants, refractive index, the band-gap of the thin film and depends nature of the film material [11]. A (CE595 Double Beam Digital U.V spectrophotometer, CECIL instrument) was used to record the optical transmission for CdS films. from which the absorption coefficient $(\alpha)$ calculated [12]:

$$
\alpha=-\ln \frac{(T)}{d}
$$

where $\mathrm{d}$ is the film thickness, and $\mathrm{T}$ is the transmission.

\section{RESULTS AND DISCUSSION}

\section{1. Influence of Deposition conditions}

\section{1. 1. Temperature of the Bath}

$\mathrm{CdS}$ could be deposited on the substrate when the ionic product of $\mathrm{Cd}^{2+}$ and $\mathrm{S}^{2-}$ exceeds the solubility product of $\mathrm{CdS}\left(\mathrm{Ks}=10^{-28}\right)$. Figure 1 , shows the growth kinetic of $\mathrm{CdS}$ thin films. All the curves show a linear increase with reaction times and bath temperatures with no saturation. Growth rate of deposited films Fig. 2) gradually decreases with deposition time, and increases with bath temperature. Heating the solution, helps the decomposition of thiourea and also provides kinetic energy to the ions, resulting in increased number of collisions and hence combination to form $\mathrm{CdS}$ particles which cannot be adsorbed. $\mathrm{CdCl}_{2}$ has higher stability constant which means much slower release of $\mathrm{Cd}$ ions and consequently a thinner CdS film. 


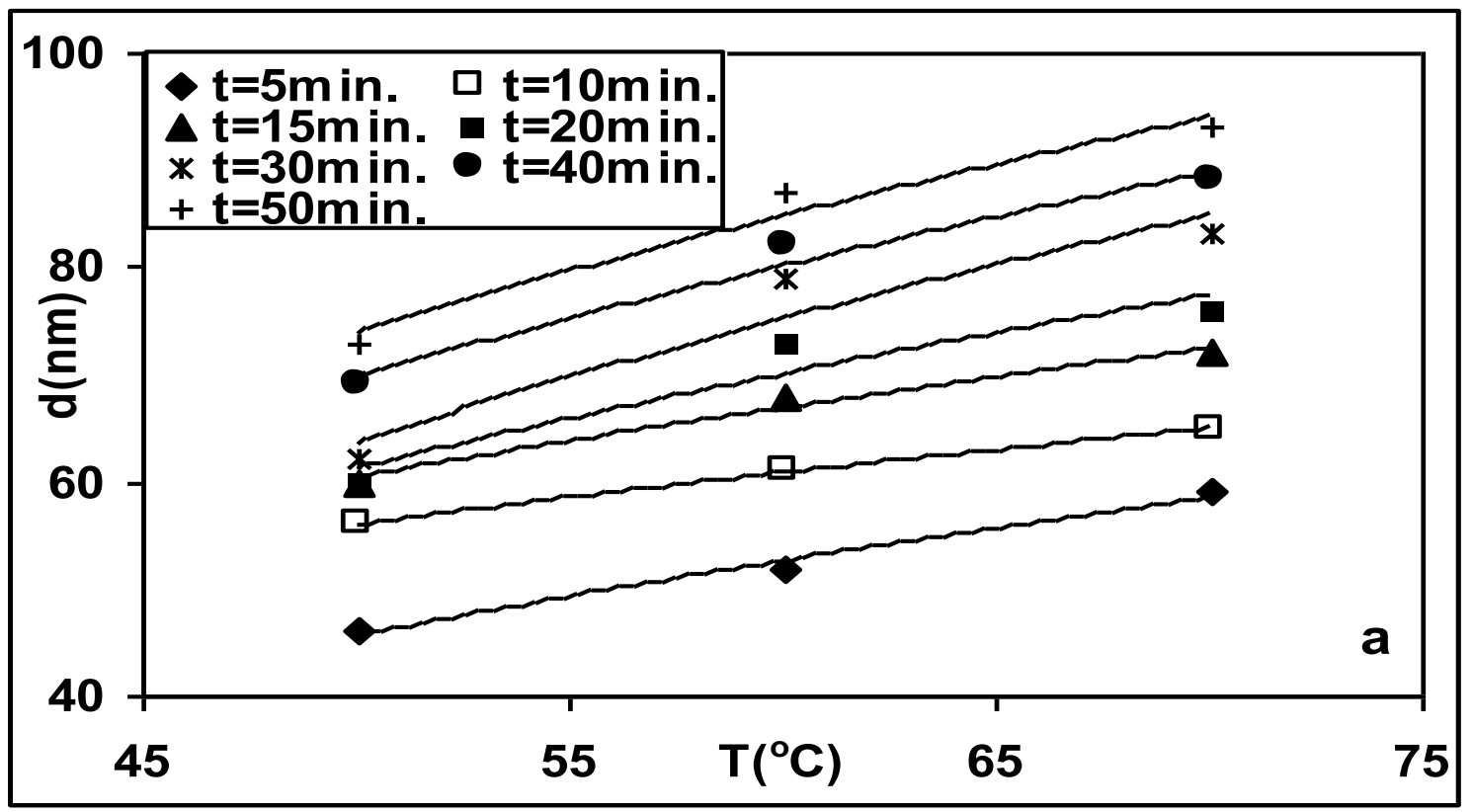

(a)

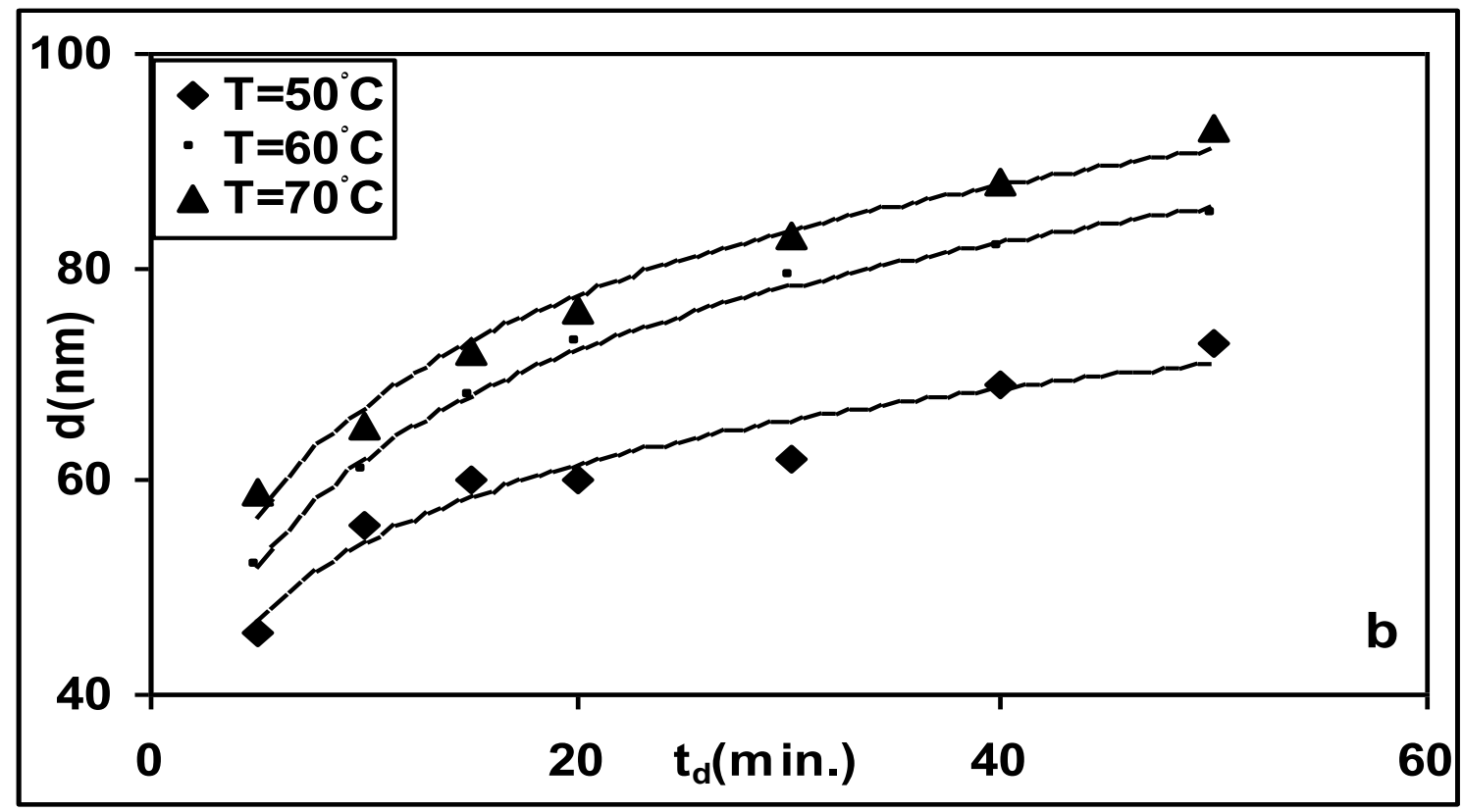

(b)

Fig. 1. Variation of CdS thickness versus (a) bath temperature at different deposition time and (b) deposition time at different temperature. 


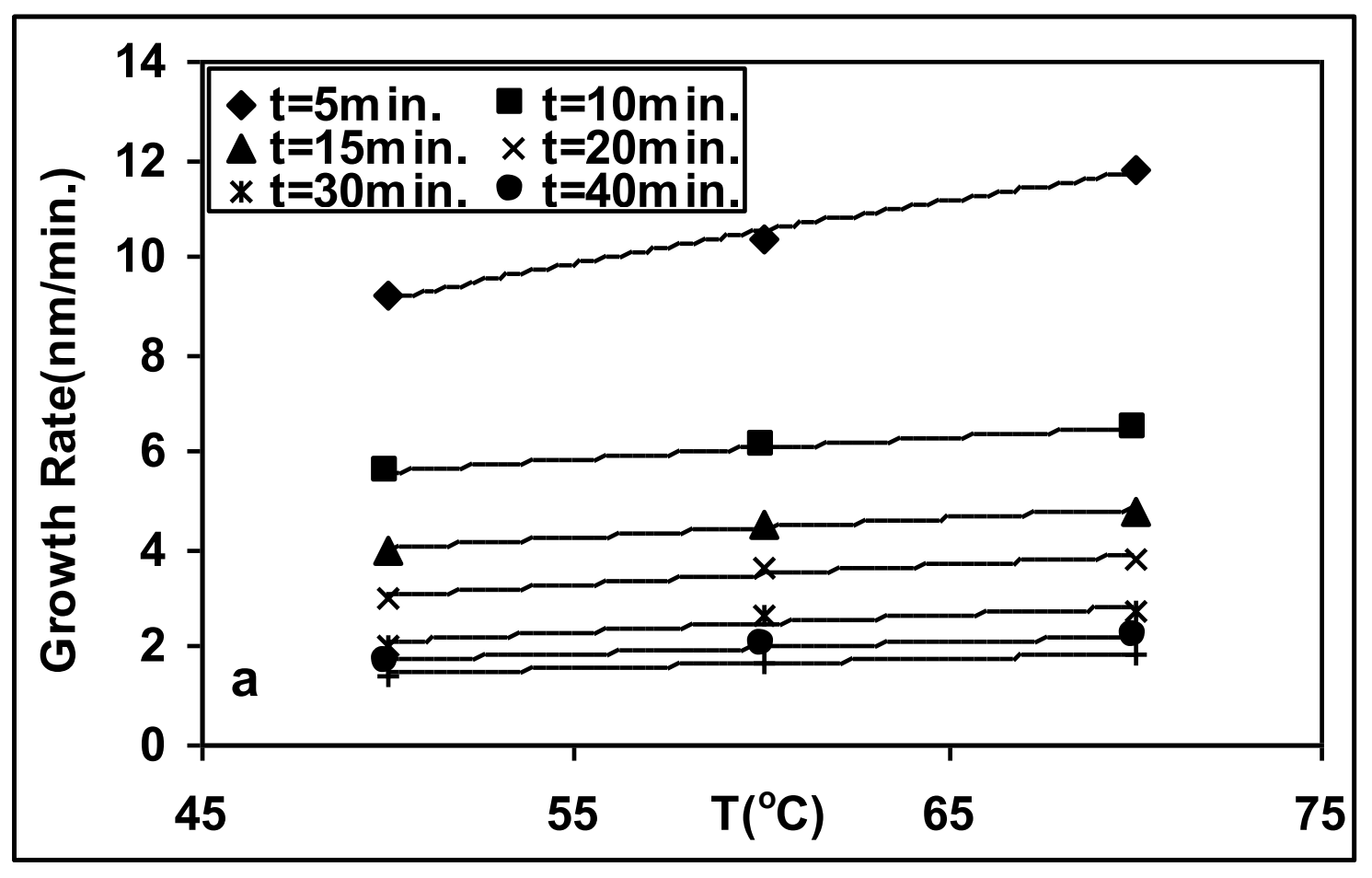

(a)

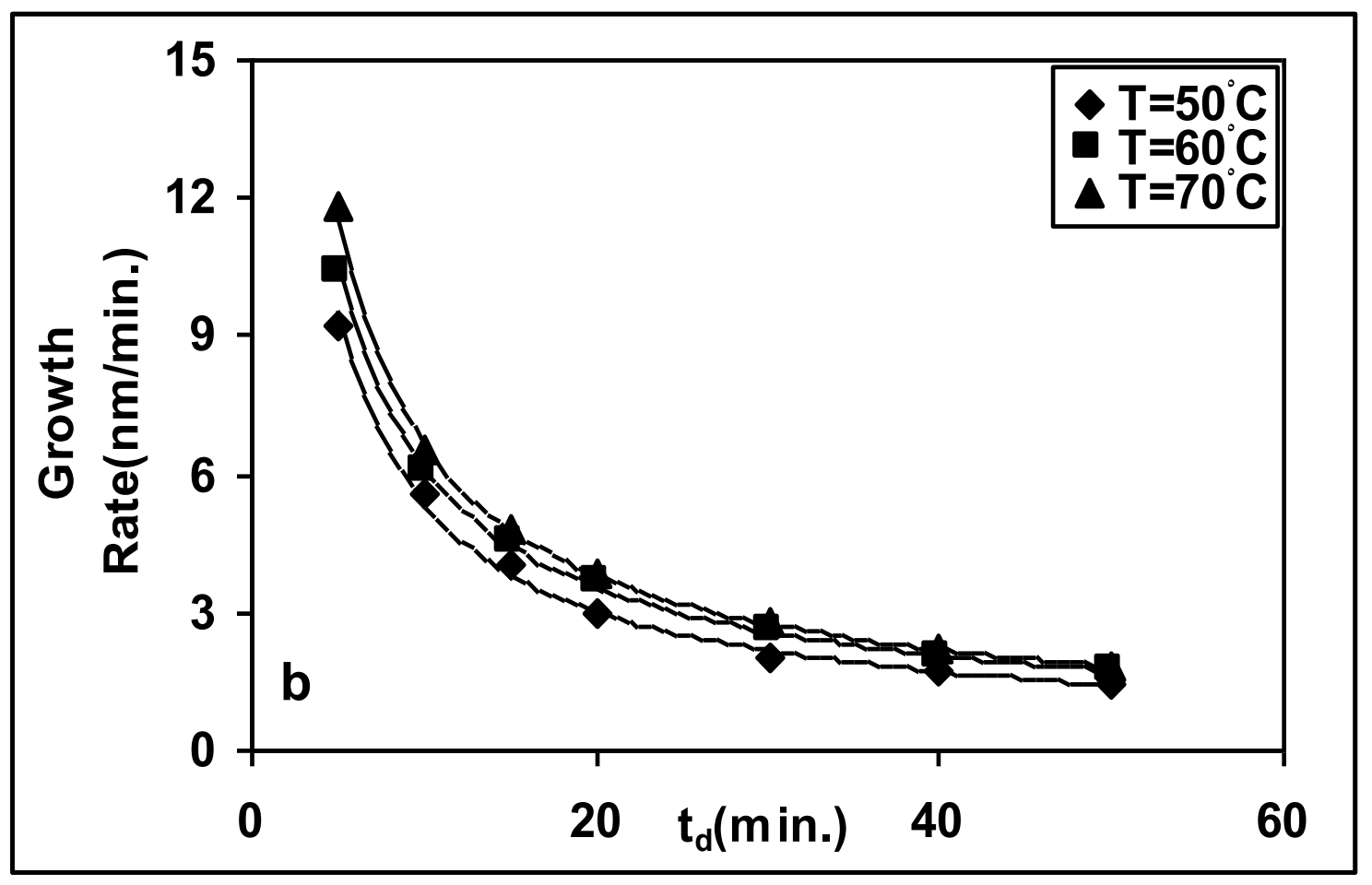

(b)

Fig. 2. Growth rate of $\mathrm{CdS}$ films using $\mathrm{CdCl}_{2}$ source as function of (a) temperature at different deposition times (b) deposition time at different temperature. 


\section{1. 2. Cadmium salt concentration effect}

The growth kinetic of the CdS thin films using different concentration of $\mathrm{CdCl}_{2}$ is shown in Fig. 3.

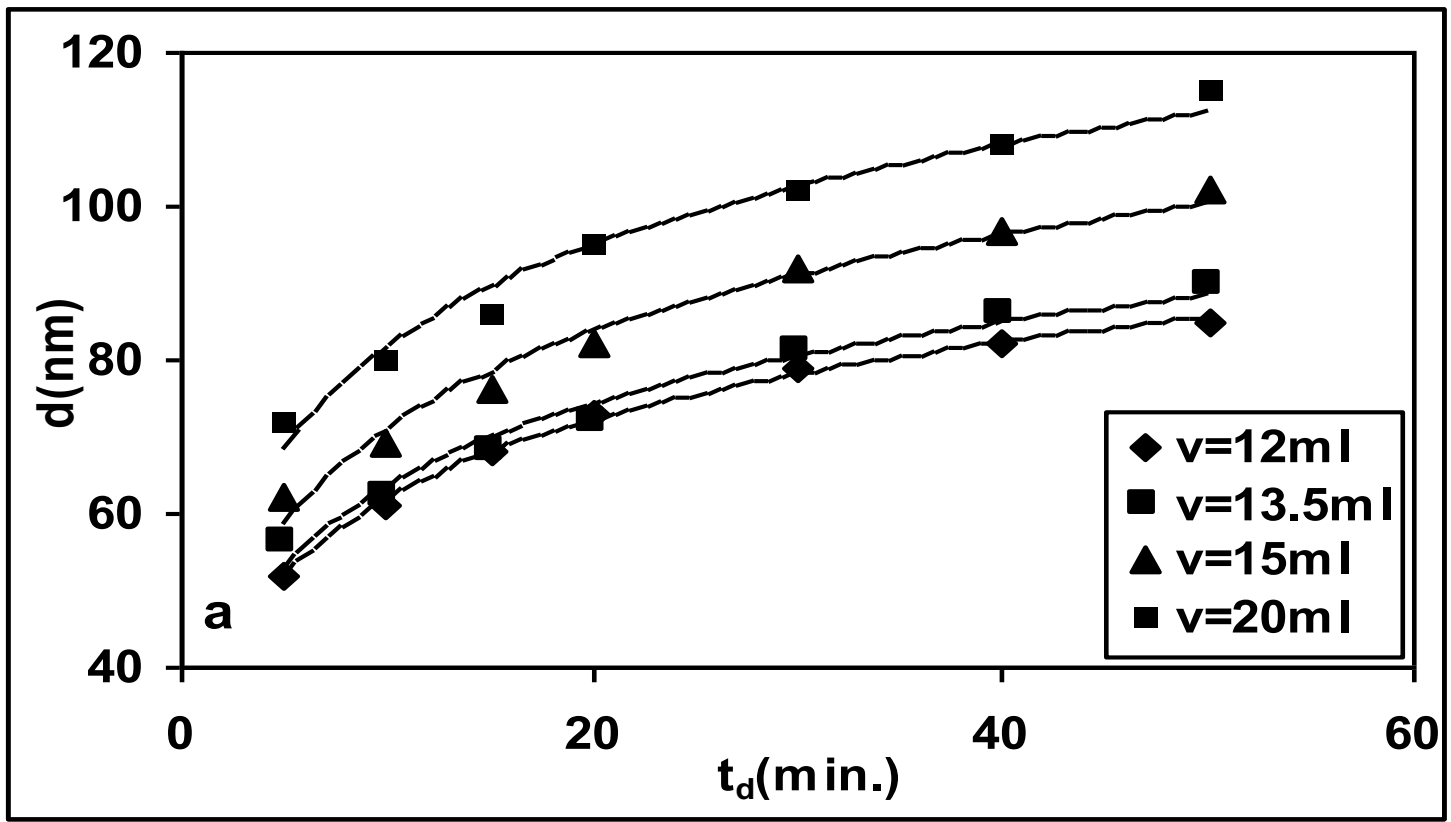

(a)

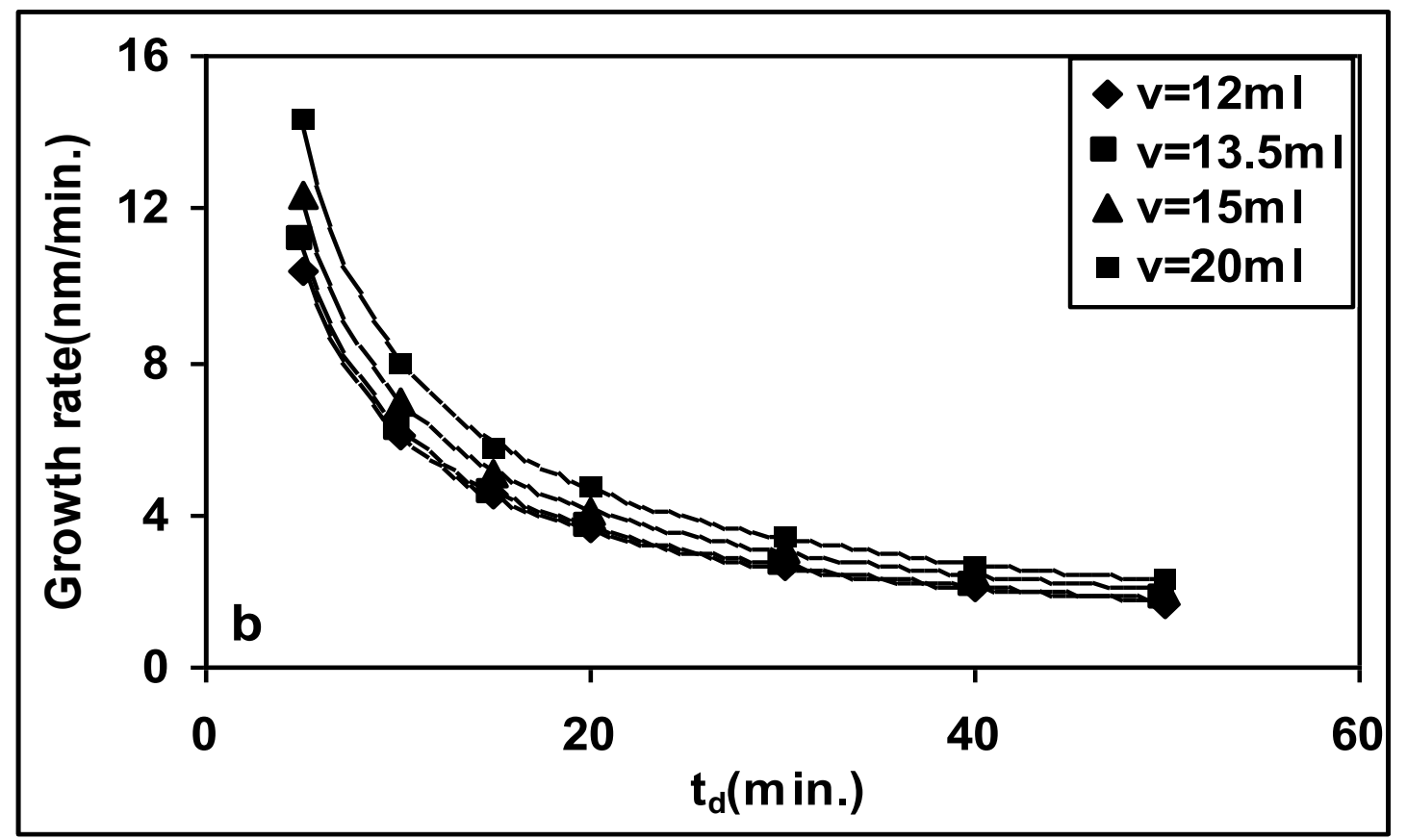

(b)

Fig. 3. (a) Variation of CdS thickness versus (a) deposition time at different $\mathrm{CdCl}_{2}$ volumes and (b) growth rate $\mathrm{VS} \mathrm{CdCl}_{2}$ volume at temperature $60^{\circ} \mathrm{C}$, deposition time $10 \mathrm{~min}$. and $\mathrm{pH}=11$. 
A fast and almost linear increase in thickness is observed at the first stages as shown in Fig. 3a. Byond this stage the thickness increases more slowly, and approaches a constant value at the longest deposition times, while growth rate decrease with increasing deposition time as shown in Fig. 3(b).

The film thickness and growth rate are directly related to the amount of cadmium ions in the reaction solution. The main features observed in the film thickness evolution are that: increasing the concentration of the cadmium ions in the CBD process produces a higher final film thickness, also longer deposition time is needed to attain the final film thickness.

In addition after a certain deposition time, the absorption and/or dissolution process predominates over the heterogonous and homogenous precipitation [11].

\section{1. 3. Effect of changing $\mathrm{KOH}$ concentrations and $[\mathrm{NTA}] /[\mathrm{Cd}]$ ratio}

The film thickness increases dramatically from almost zero (no deposition observed) at $0.5 \mathrm{ml}, 1 \mathrm{ml}, 1.5 \mathrm{ml}$, and $2 \mathrm{ml} \mathrm{KOH}$. Increasing concentration to $2.5 \mathrm{ml}$ accompanied by thickness increasing rapidly to $74 \mathrm{~nm}$. as shown in Fig. (4a), increasing the concentration up to $3.5 \mathrm{ml}$ has no influence on thickness. Beyond $3.5 \mathrm{ml}$ the film thickness decreases rapidly with $\mathrm{KOH}$ concentration.

This decreasing could be attributed to the formation of collide precipitate in the container. It's worth noting that the film thickness becomes maximum $(92 \mathrm{~nm})$ at $[\mathrm{NTA}] /[\mathrm{Cd}]$ ratio of 4 , which is almost four times the film thickness $(28 \mathrm{~nm})$ at $[\mathrm{NTA}] /[\mathrm{Cd}]$ ratio $=2$ Fig. (4b).

This proves that regardless of the Cd precursor used, the presence of $\mathrm{Cd}(\mathrm{NTA})_{4}{ }^{10-}$ complex in the solution is essential for higher thickness and faster growth rate. The film thickness increases with the $[\mathrm{NTA}] /[\mathrm{Cd}]$ ratio until it reaches its maximum at a ratio of 4 , and then decreases. It's worth noting that, till now, it was typically believed that with NTA as a complexing agent, the CdS deposition mechanism is mainly based on the formation of $\mathrm{Cd}(\mathrm{NTA})^{-}$or $\mathrm{Cd}(\mathrm{NTA})_{2}{ }^{4-}$ complex in the solution.

However, according to our findings the film thickness increased by a factor of three or more when the $[\mathrm{NTA}] /[\mathrm{Cd}]$ ratio increased from 2 to 3 , and then increased by a factor of 4 or more when this ratio increased from 2 to 4 . We believe this suggests that the main deposition mechanism is based on the presence of $\mathrm{Cd}(\mathrm{NTA}){ }_{3}{ }^{7-}$ and/or $\mathrm{Cd}(\mathrm{NTA})_{4}{ }^{10-}$ complexes in the solution.

It was noticed that when the $[\mathrm{NTA}] /[\mathrm{Cd}]$ ratio was less than 3 , homogeneous reaction dominated the deposition process within a few minutes which in turn lead to a quick depletion of the $\mathrm{Cd}$ ions in the solution, and very thin films were obtained.

This indicates that for a ratio less than 3 , the stability constant of the $\mathrm{Cd}$ complex formed in the solution is too low to ensure the slow release of $\mathrm{Cd}$ ions in the main bath. This may explain why the undesirable homogeneous reaction dominated the deposition process. It was also noticed that when this ratio goes beyond 4 , the solution remains clear with no homogeneous reaction during most of the deposition time indicating a very limited release rate of $\mathrm{Cd}$ ions in the solution.

Apparently, the stability constant of the Cd (NTA) ${ }_{\mathrm{x}}{ }^{\mathrm{y}-}$ complex, where $\mathrm{x}$ is larger than 4 , is too high. This means fewer $\mathrm{Cd}$ ions are available for $\mathrm{CdS}$ deposition. Obviously, the stability constant of the $\mathrm{Cd}$ complex formed when the $[\mathrm{NTA}] /[\mathrm{Cd}]$ ratio is about 4 seems to have a moderate value so that the growth rate is maximum at this particular ratio, and as a result, this ratio is optimu. 


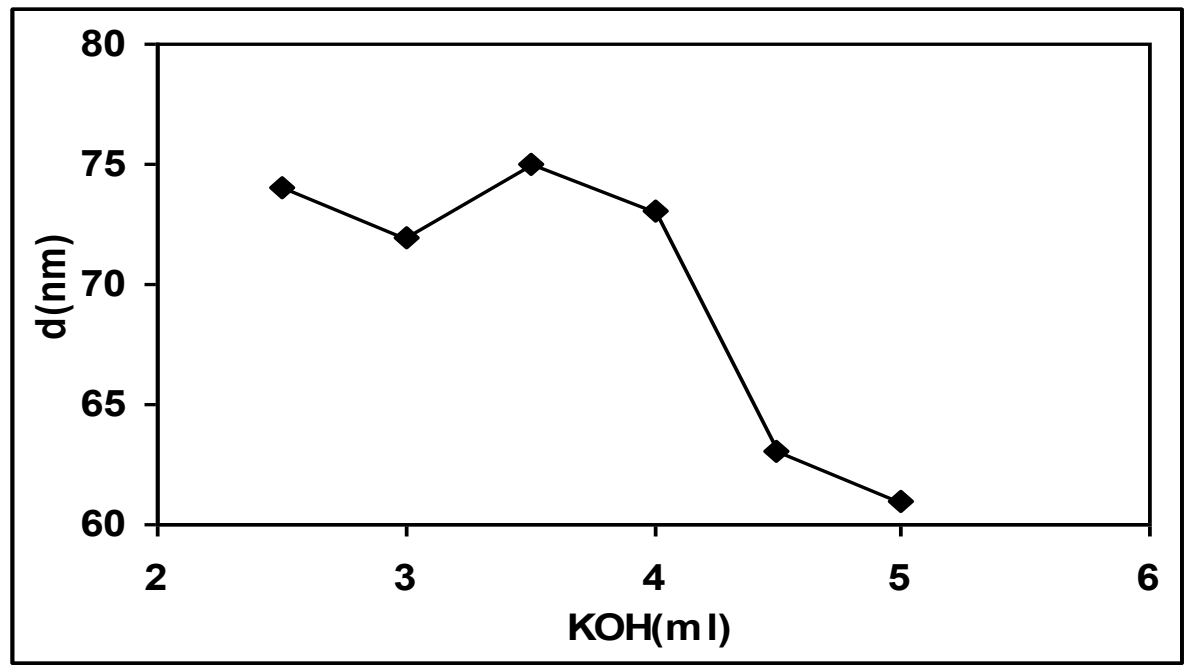

(a)

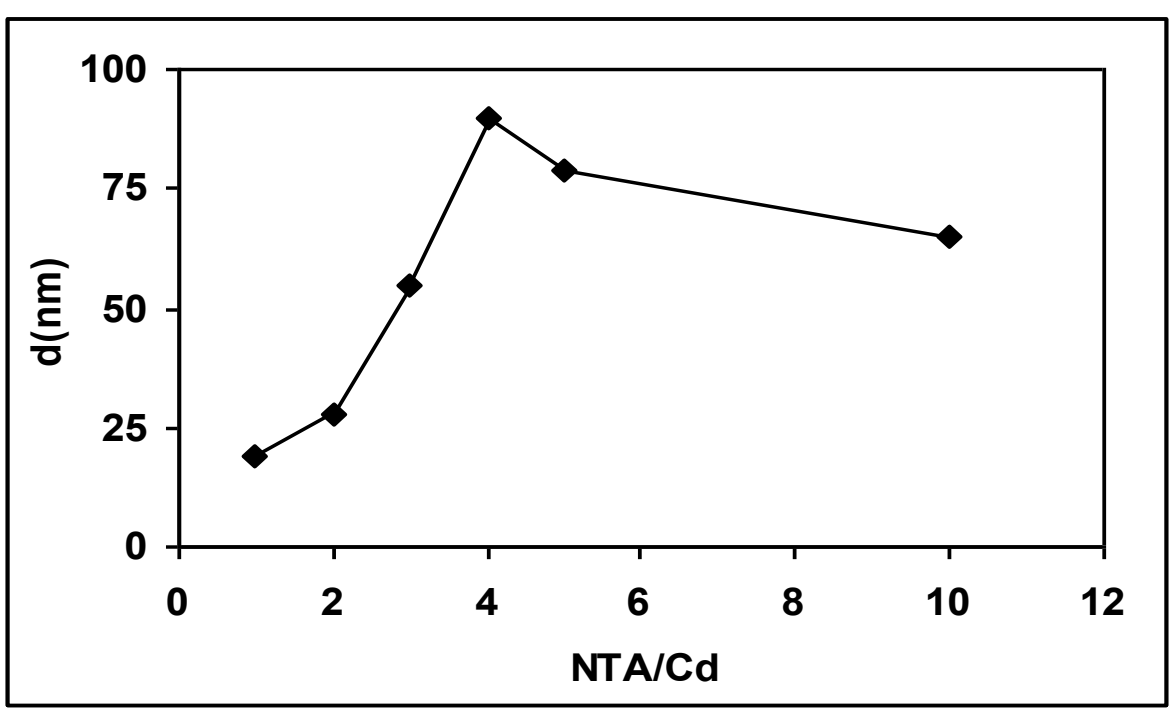

(b)

Fig. 4. Film thickness dependence on (a) $\mathrm{KOH}$ concentration, (b) $[\mathrm{NTA}] /[\mathrm{Cd}]$ ratio using $\mathrm{CdCl}_{2}$ source at temperature $60^{\circ} \mathrm{C}$, deposition time $10 \mathrm{~min}$. and $\mathrm{pH}=11$.

\section{2. Structure Properties: Crystal structure and phase}

The crystal structure of the films was determined by XRD (using $\mathrm{Cu} K \alpha$ radiations, $\lambda=$ $1.54 \AA$ ). XRD analysis confirms that the deposited films are polycrystalline with less no preferred planes at low deposition time as shown in Fig. 6. The main peak correspond to the plane (111) appears at angle $2 \theta=26.6^{\circ}$, become predominated with increasing deposition time. Although increasing deposition time should increase film thickness but this thickness increasing have no influence on the peak intensity. At higher diffraction angle (200) plane belong to $\mathrm{CdO}$. 


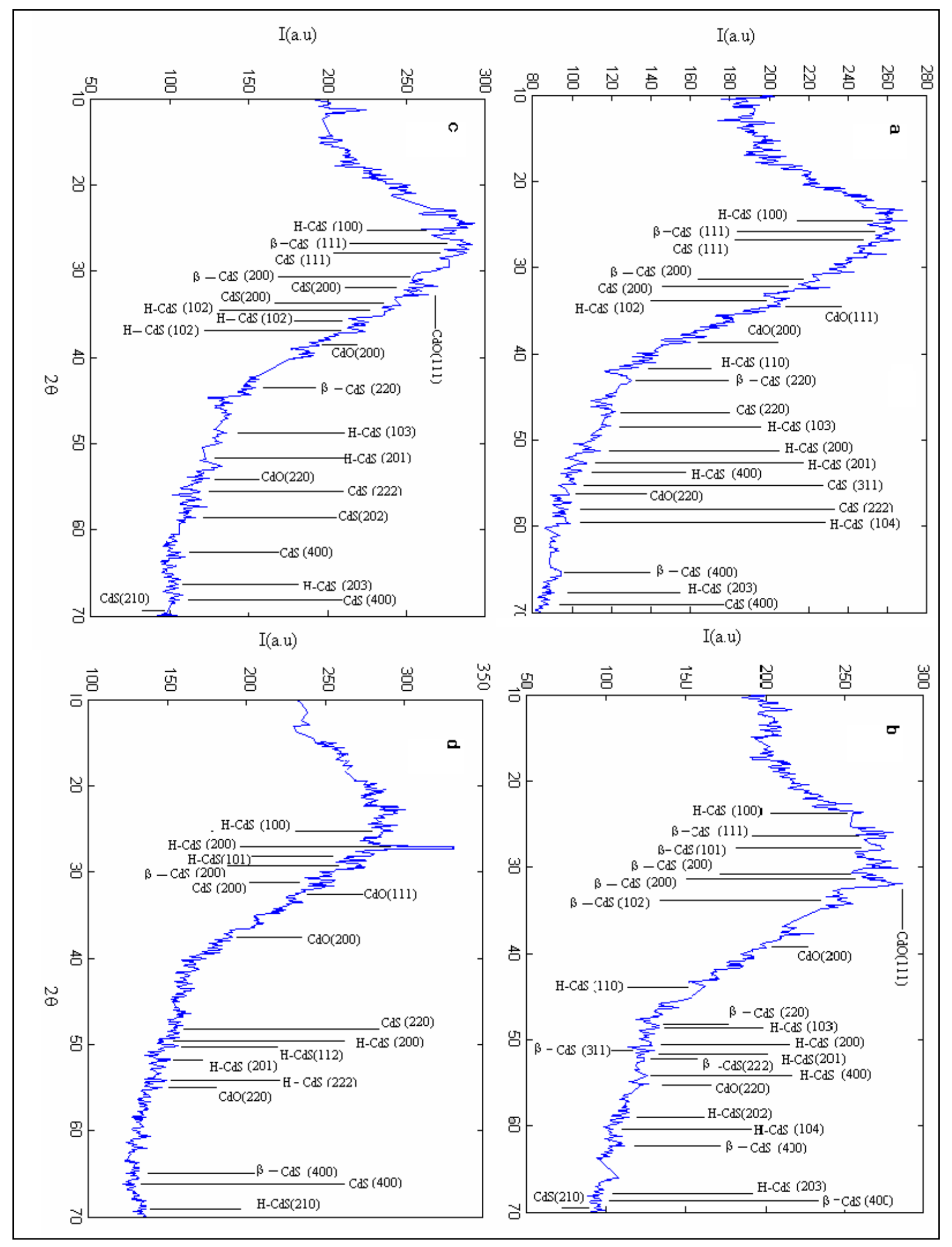

Fig. 6. Typical XRD pattern of CBD-CdS thin film using $\mathrm{CdCl}_{2}$ source, at temperature $50^{\circ} \mathrm{C}, \mathrm{pH}=11$ and deposition time at (a) $5 \mathrm{~min}$. (b) $10 \mathrm{~min}$. (c) $15 \mathrm{~min}$. and (d) $20 \mathrm{~min}$. 
The origin of the impurity could be deriving from oxidation processes (i.e. traces of water present in the film or air) or from reaction of any preformed cadmium hydroxide. Further, the type of substrate or growth condition determines the number of XRD reflection peaks.

It is also noticeable that the width of the main peak in film deposited at longer deposition time is smaller than for other samples, this could be due to reduced strain within the film, or an increase in grain size.

\section{2. 1 X-ray diffraction analysis}

Using the equations (2-6), the results of x-ray diffractgrams can be tabulated. Tables 1 shows the influence of deposition time on the microstructure of deposited CdS .

Table 1. X-ray analysis of samples deposited at $50^{\circ} \mathrm{C}$ using $\mathrm{CdCl}_{2}$.

\begin{tabular}{|c|c|c|c|c|c|c|c|}
\hline $\begin{array}{c}\mathbf{t} \\
\text { (min.) }\end{array}$ & $\begin{array}{c}d \\
(\mathbf{n m})\end{array}$ & $\begin{array}{c}2 \theta \\
\text { (degree) }\end{array}$ & $\begin{array}{c}\beta \\
(\mathrm{rad}) \\
\times 10^{-3}\end{array}$ & $\begin{array}{c}D \\
(\mathbf{n m})\end{array}$ & $\begin{array}{c}\delta \\
\text { (lines } / \mathbf{m}^{2} \text { ) } \\
\times 10^{14}\end{array}$ & $\begin{array}{c}N \\
\times 10^{12}\end{array}$ & $\begin{array}{c}\epsilon \\
\times 10^{-3}\end{array}$ \\
\hline 5 & 46 & 26.6 & 1.745 & 106.957 & 0.874 & 37.595 & 0.324 \\
\hline 10 & 53 & 26.6 & 1.396 & 133.69 & 0.559 & 22.180 & 0.259 \\
\hline 15 & 60 & 26.8 & 1.047 & 196.974 & 0.257 & 7.850 & 0.1759 \\
\hline 20 & 68 & 26.8 & 1.0122 & 203.78 & 0.240 & 8.035 & 0.1700 \\
\hline
\end{tabular}

The variation in grain size with deposition time is shown in Fig. 7. The grain size exhibit saturation at long deposition time.

The increase in grain size means a decrease in grain boundaries (lesser scattering area) and pores in the thicker films as compared to the thin films.

Large scattering centers in the lattice due to mismatch at film/ substrate interface gave rise to defects in thin films. The results could be explained by adopting the survivor of the fastest model [14].

According to this model nucleation with various orientations can be formed at the initial stage of the deposition and each nucleus competes to grow but only nuclei having the fastest growth rate survive [15].

Such results have been already seen by others $[8,15]$, More probably this is due to the variation in the surface of the substrate, in short time the film deposited on the glass substrate where the nucleation centers density is high. While in longer time the layers deposited on the already deposited CdS layer. 


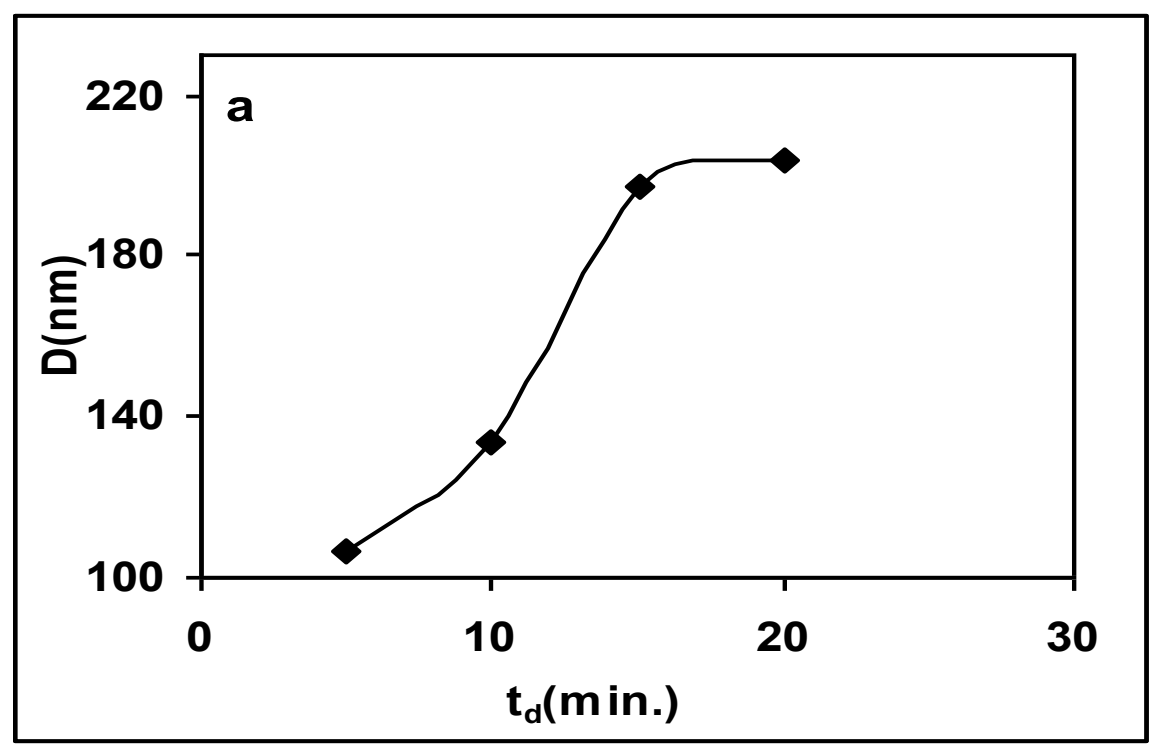

Fig. 7. Grain size as a function of density as deposition time.

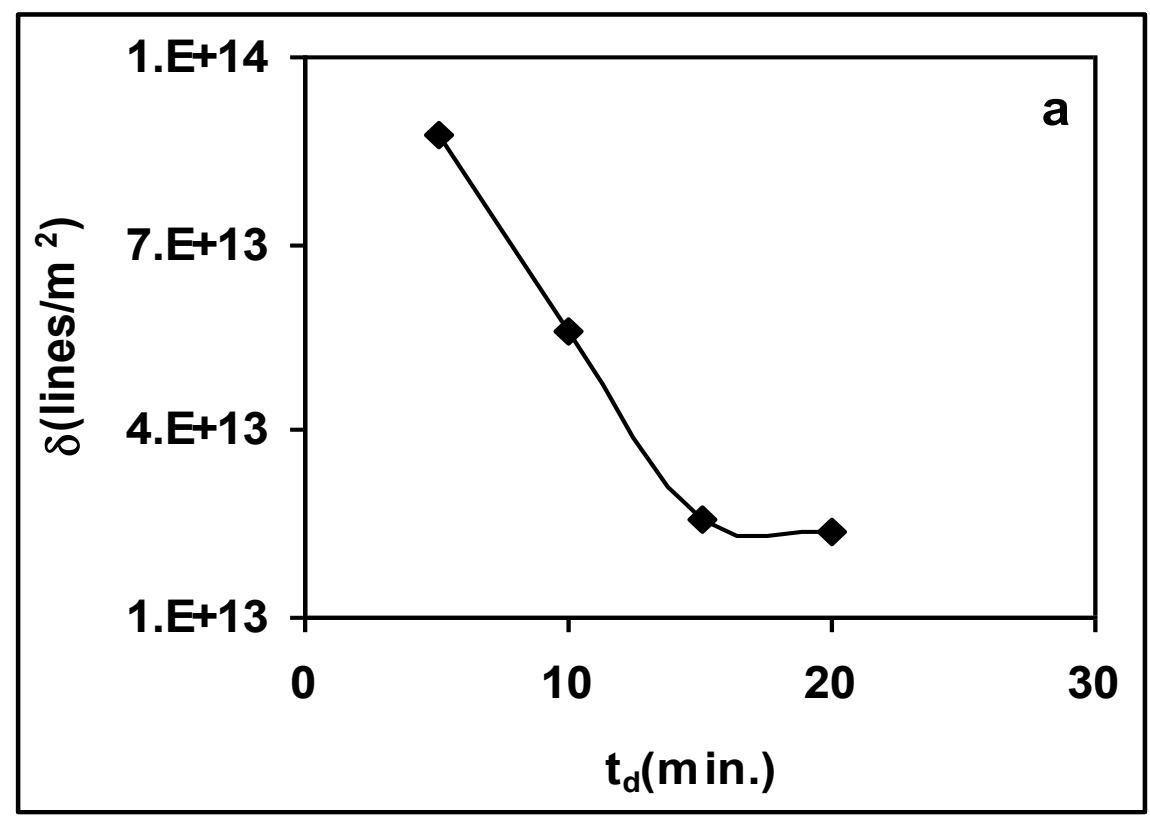

Fig. 8. Dislocation a function of deposition time.

The dislocation density decreases with deposition time as shown in Figure 8 . The decreasing is sharp with short deposition time while in longer time the inverse change takes place. Such behavior could be due to the change in grain size accompanied short and longer time deposition. Figures 9 shows the variation in the films strain as a function of deposition time, the decreasing in the strain with time is probably due to the enhancement in the degree of crystallite of deposited film due to the increasing in grain size. 


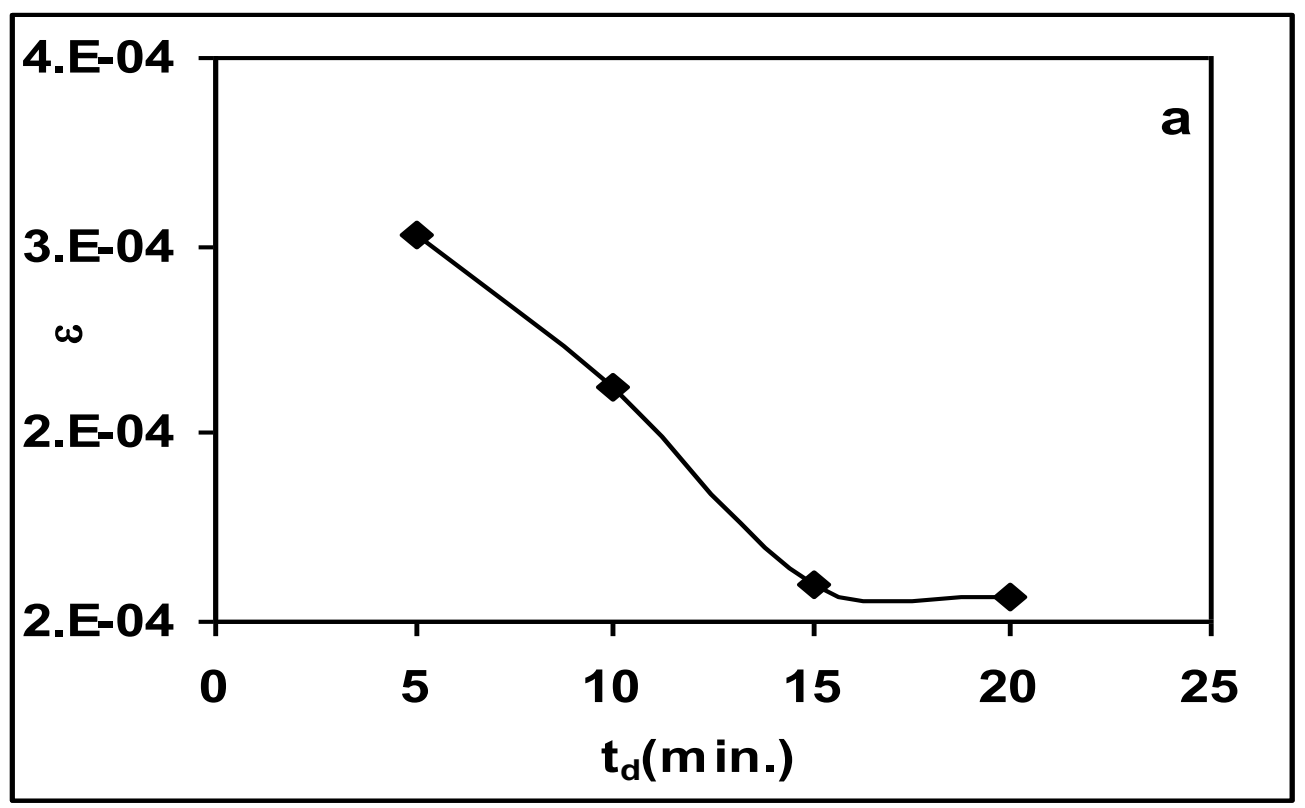

Fig. 9. CdS films strain as a function of deposition time.

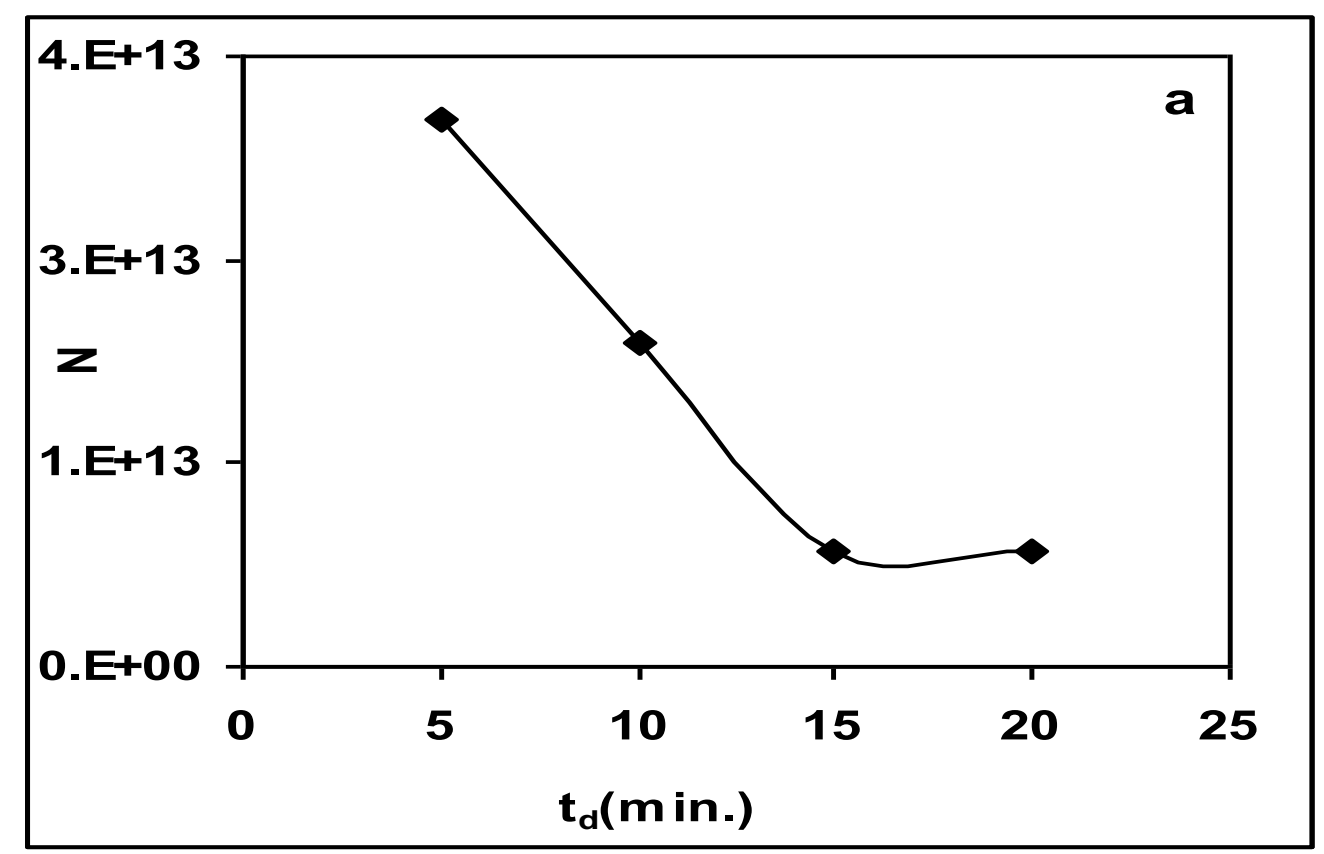

Fig. 10. Number of crystallites as a function of deposition time.

The decreasing in number of crystallites with deposition time is shown in Figure 10. The decreasing accompanied is that the nucleation with various orientations can be formed at the initial stage of the deposition and each nucleus competes to grow but only nuclei having the fastest growth rate survive. 


\section{CONCLUSION}

In this work, we have showed that deposition time and path temperature play a dominant role in controlling the film thickness, growth rate of chemically deposited CdS polycrystalline. On the other hand, XRD investigations show that the grain size increases with deposition time while the dislocation density decreases with deposition time. Also the strain decrease in with time due to the enhancement in the degree of crystallite of deposited film. The energy gap decreases as the bath temperature increased. The Optical absorption study reveals that $\mathrm{PbS}$ thin films have allowed direct transitions, with band gap energy varies from 2.31 to $2.43 \mathrm{eV}$ depending on deposition conditions.

\section{References}

[1] E. Marín, J. Santoyo, A. Calderón, O. Vigil-Galán, G. Contreras-Puente, Journal of Applied Physics 107(12) (2010) 123701.

[2] O. Vigil-Galán, et. al., Thin Solid Films 515(15) (2007) 6085-6088.

[3] M. Sam, M.R. Bayati, M. Mojtahedi, K. Janghorban Applied Surface Science 257 (2010) 1449-1453.

[4] N. Romeo, A. Bosio, R. Tedeschi, A. Romeo, V. Canevari, Sol. Energy Mater. Sol. Cells 58 (1999) 209.

[5] Ali M. Mousa, Adawiya J. Haider, Selma M. Hassan Al-Jawad, Journal Material Science and Engineering 5(2) (2011)

[6] K. Durose, P. R. Edwards, D. P. Halliday, J. Cryst. Growth 197 (1999) 733.

[7] K. Ravichandran, P. Philominathan, Applied Surface Science 255 (2009) 5736-5741.

[8] A. Goswami (2008), Thin Film Fundamentals, New Age Publications (Academic).

[9] Randall M. German, Seong Jin Park Handbook of Mathematical Relations in Particulate Materials Processing", (Wiley Series on Processing of Engineering Materials, WileyInterscience Publications (2008)".

[10] G. Hodes, Chemical Solution Deposition of Semiconductor Films, Marcel Dekker (2003).

[11] E. I. Ugwu, D. U. Onah, The Pacific Journal of Science and Technology 8(1) (2007) 155-161.

[12] H. Moualkia, S. Hariech, M. S. Aida, Structural and optical properties of CdS thin films grown by chemical bath deposition, Thin Solid Films, Article in press. (2009)"

[13] A. van der Drift, Philips Research Reports 22 (1967) 267-288.

[14] J. M. Dona, J. Herrero, J. Electrochem. Soc. 144 (1997) 4081-4091.

[15] M. B. Ortuñ Lo'peza, J. J. Valenzuela-J'aureguia, M. Sotelo-Lermab, A. MendozaGalva'na, R. Ram'irez-Bona, Thin Solid Films 429 (2003) 34-39.

[16] Adawiya J. Haider, Ali M. Mousa, Selma M. H. Al-Jawad, Journal of Semiconductor Technology and Science 8(4) (2008) 326-332. 
[17] Nadir Fadhil Habubi, Sami Salmann Chiad, Saad Farhan Oboudi, Ziad Abdulahad Toma, International Letters of Chemistry, Physics and Astronomy 4 (2013) 1-8.

[18] Saad F. Oboudi, Nadir F. Habubi, Ghuson H. Mohamed, Sami S. Chiad, International Letters of Chemistry, Physics and Astronomy 8(1) (2013) 78-86.

[19] J. A. Najim, J. M. Rozaiq, International Letters of Chemistry, Physics and Astronomy 10(2) (2013) 137-150.

[20] Majid H. Hassouni, Khudheir A. Mishjil, Sami S. Chiad, Nadir F. Habubi, International Letters of Chemistry, Physics and Astronomy 11 (2013) 26-37.

[21] K. K. Patankar, International Letters of Chemistry, Physics and Astronomy 1 (2014) $1-8$.

[22] Hanan R. A. Ali, International Letters of Chemistry, Physics and Astronomy 8 (2014) 47-55. 